\title{
Ewa Woźniak
}

Instytut Filologii Polskiej i Logopedii, Uniwersytet Łódzki

\section{O stylistycznym zróżnicowaniu dawnej leksyki - na przykładzie oficjalnych i potocznych nazw dziecka nieślubnego}

Nazwy dzieci nieślubnych stanowią dobrą podstawę do rozważań nad stylistycznym zróżnicowaniem dawnej leksyki przynajmniej z dwóch powodów. Pojęcie dziecka spoza związku małżeńskiego było obecne w dawnym prawie, choćby miejskim, i jako takie miało terminologiczne wykładniki, ale było to również pojęcie funkcjonujące $w$ języku potocznym. Nasuwa się więc pytanie, czy pojęcie prawne i pojęcie potoczne były wyrażane za pomocą tych samych, czy różnych jednostek językowych, a więc - czy repertuar dawnych nazw dziecka nieślubnego był stylistycznie zróżnicowany. Nazwy dziecka spoza związku małżeńskiego wydają się dobrym polem do takich obserwacji też z tego powodu, że tworzą zbiór dość liczny już w dobie staropolskiej, a to pozwala na badanie występowania poszczególnych jednostek w tekstach powstałych w różnych sytuacjach komunikacyjnych. W niniejszym szkicu przyjrzałam się pod tym kątem trzem nazwom: wyleganiec, pokrzywnik i bękart, z czasowym ograniczeniem do doby staropolskiej oraz wieku XVI.

Społeczne wykluczenie dzieci pozamałżeńskich, a także ich obyczajowa dyskredytacja były okolicznościami sprzyjającymi nominacjom o charakterze ekspresywnym. Dlatego liczną grupę nazw określających dziecko z nieprawego łoża w historii polszczyzny Artur Rejter zaliczył do leksyki ekspresywnej [Rejter 2006: 130]. W kategorii semantycznej DZIECKO Z NIEPRAWEGO ŁOŻA umieścił takie nazwy, jak bękart i jego liczne derywaty, baster $\mathrm{z}$ wariantami i derywatami, fotarlę, mamzer, ponadto jako podgrupę w tej kategorii wyróżnił takie jednostki, jak wyleganiec, najduk, nalezionek, podmiotek, podrzutek, pokrzywnie, pokrzywnik, samosiejka, samosiejek, wyleganiec, najduch, najdek, nabytniak, przyplodek ${ }^{1}$ ze względu na obecność semantycznego komponentu

1 Podaję w takiej kolejności jak autor, a więc według tego, w jakich słownikach są najdawniejsze poświadczenia wymienionych leksemów. 
'bycie znalezionym, podrzuconym, nieoczekiwanym'. Leksyka ekspresywna w pracy Rejtera została wyodrębniona na podstawie szczegółowo opisanych przez autora kryteriów kontekstowych [Rejter 2006: 73-105]. Wydaje się jednak, że warto byłoby - w ocenie oficjalności lub potoczności nazw - uwzględnić również rodzaj czy gatunek tekstu, zależność pomiędzy typem, rangą tekstu a stosowanymi w nich nazwami. Tą wypowiedzią mam nadzieję włączyć się w dyskusję nad możliwością i metodami badań stylistycznego nacechowania dawnej leksyki.

Nazwy dzieci spoza związku małżeńskiego w polszczyźnie były już przedmiotem opisu, kolejne opracowania oświetlały różne aspekty tego nazewnictwa. Przy okazji wygłaszano również sądy na temat ich stylistycznego nacechowania - dawniej i dziś. Przyczynek do tej tematyki stanowią uwagi o nazwach dziecka nieślubnego w Liber chamorum, które w związku z charakterystyką XVII-wiecznego stylu niskiego sformułował Bogdan Walczak:

Ze szczególną uwagą tropił autor Liber chamorum nieprawe pochodzenie „diktusów”. W związku z tym pojawia się w tekście odpowiednie słownictwo. Bękart (np. Jąn, bękart p. Jędrzeja Chwaliboga 41) i bękartka (np. Siostrę tych, bękartkę, pojął jakiś Chłopicki 45) to wyrazy najmniej nacechowane stylistycznie. W Liber chamorum pojawia się jednak także arcybękart: Ten bękart z małpą mieszkał bez ślubu i miał arcybękarty z nią 115, arcybękartka [...] i najbardziej potoczny, najbardziej charakterystyczny dla stylu niskiego bęś: Tego bęsia, jak się urodzieł, dał beł chować opat do folwarku do Mniszowa 374. [...] Wyjątkowo raz pojawia się basztardus: chłopski syn, bodaj nie księży basztardus 666². [Walczak 1992: 185]

Wymienione nazwy Walczak omawia w grupie ,wyzwiska, wyrazy obelżywe, wulgaryzmy i obscena" [Walczak 1992: 183].

W artykule Doroty Rembiszewskiej Nazwy nieślubnego dziecka w historii i dialektach polszczyzny, który ma głównie charakter rejestrujący, pojawia się w zakończeniu następująca konkluzja:

Jak wynika z przedstawionego przeglądu nazw, najbardziej obfite nazewnictwo 'dziecka nieślubnego' znajdujemy w dawniejszej polszczyźnie. Do dzisiaj z tych dawnych zachowały się nazwy obce, jak bękart, bastard, które właściwie należą do stylu książkowego bądź występują w gwarach. We współczesnej polszczyźnie w związku ze zmianami obyczajowymi, akceptacją dzieci spoza

2 Wszystkie wyróżnienia - E.W. 
związków małżeńskich, właściwie brak jednowyrazowych nazw. [Rembiszewska 2008: 63-64]

Nominacje o charakterze analitycznym zebrała Monika Kresa [2014], ekscerpując źródła leksykograficzne i tekstowe od XVI wieku do czasów współczesnych. Autorka postawiła sobie za cel określenie relacji pomiędzy nazwami jednowyrazowymi i opisowymi, którą to intencję dobrze oddaje tytuł artykułu: Bękart versus dziecko naturalne - różne sposoby mówienia o dzieciach zrodzonych poza związkiem matżeńskim (XVI-XXI wiek) [Kresa 2014: 154]. Spośród różnych szczegółowych wniosków, które sformułowała Kresa, ważny w kontekście moich dalszych rozważań jest taki:

Określenia analityczne powstają głównie na użytek tekstów oficjalnych prawnych i biblijnych i pełnią w nich niejako funkcję eufemizmów wobec rzeczowników bękart i bastard, które niewątpliwie od początku funkcjonowania w polszczyźnie miały wydźwięk negatywny. [Kresa 2014: 167]

Zgadzając się z badaczką co do oficjalnego charakteru nazw analitycznych, chciałabym zastanowić się nad wartością stylistyczną niektórych nazw jednowyrazowych. Jak już zostało powiedziane, nazewnictwo dzieci spoza związku małżeńskiego jest w dawnej polszczyźnie bogate - można by powiedzieć, że z tym bogactwem nie poradzili sobie autorzy Słownika pojęciowego języka staropolskiego, którzy podzielili językowe wykładniki tego pojęcia pomiędzy dwie różne kategorie: 2.1.2. Osoby urodzone w pełnej rodzinie. Osoby urodzone w niepełnej rodzinie oraz 2.5.1.1. Krewni. Powinowaci. W pierwszej z wymienionych kategorii znalazły się takie jednostki, jak baster, basterka, bekart oraz pokrzywnik ${ }^{3}$, w drugiej - wyleganiec i wyleganica [SPJS].

Przyglądając się użyciom staropolskich nazw dzieci pozamałżeńskich, możemy zaobserwować pewne prawidłowości, które - jak sądzę - świadczą o przynależności do różnych rejestrów stylistycznych. Na przykład występowanie nazwy wyleganiec ograniczone jest do staropolskich tekstów prawnych, a konkretnie do ortyli, w których ma liczne poświadczenia, np.: ,Wyleganiec albo jego dzieci mogą dobrze swe jimienie dać albo przedać [...] OrtMac 48v, 21-22” [Korpus... 2017]; „Dalej wyleganiec możeli i jego dzieci siedzieć w ławicy albo w ktorem urzędzie jako małżeński lud? OrtMac 31" [Korpus... 2017]. Rejestrowana jest również forma żeńska wyleganica: „Gdyby wyleganiec pojął w małżeństwo wyleganicę OrtOssol 30,3" [Sstp, hasło wyleganica].

3 Poza wymienionymi są tu również odesłania do składników nazw o charakterze analitycznym. 
Poza ortylami wyleganiec odnotowany został w Biblii królowej Zofii („Nie wynidzie wyleganiec (non ingredietur mamzer), jenże jest z sprośnej niewiasty urodzon w kościoł boży BZ Deut 23,2") oraz Wokabularzu trydenckim [Sstp, hasło wyleganiec]. Co ciekawe, ten interesujący neologizm nie wykazuje zależności ani od podstawy łacińskiej, ani niemieckiej, ani czeskiej. W niemieckich ortylach ma on odpowiedniki: unehelich geboren, unehelicher Geburt, unehelich geborener Mann, uneheliche Frau [Bily, Carls, Gönczi 2011: 249-250], w łacińskich - vir illegitime natus, illegitimus vir [Sstp, hasło wyleganiec]. Zdarza się, że w wersji polskiej towarzyszy mu wyrażenie o synonimicznej treści, np. niem. unehelich geboren przełożono: ,wyleganiec, co nie $<\mathrm{z}>$ stadła małżeńskiego sie narodził” [Bily, Carls, Gönczi 2011: 249], albo: „Gdyby człowiek z jinej strony był, a nań by słyszeć, iż jest wyleganiec albo bękart OrtMac 27" [Korpus... 2017]. Wyleganiec został wprowadzony w Biblii królowej Zofii jako tłumaczenie łac. mamzer, zaś w Wokabularzu trydenckim dodany do łac. spurius: „Spurius wyleganiec $\mathrm{sa}<\mathrm{n}>$ gui $<\mathrm{ni}>\mathrm{s}$ peccatorum progenies” [Sstp, hasło wyleganiec]. W czeskiej Biblii Taborskiej odpowiedni werset brzmi: „Newegde ženimcyc genž gest z prazdne nevestky vrozen w kostel boži až do desateho pokolenie [...] Deut 23,2" [Urbańczyk, Kyas 1965-1971: 282].

W XVI wieku wyleganiec jest już wyrazem rzadko używanym. SPXVI nie wymienia go wśród synonimów bękarta [SPXVI, hasło bękart], natomiast $\mathrm{w}$ indeksie elektronicznym odnotowuje wylegańca jednorazowo [SPXVIe]. Był to wyraz znany Bartłomiejowi z Bydgoszczy, który zapisał go trzykrotnie, w tym dwa razy jako polską glosę w słowniku z 1544 roku, nieobecnym w kanonie źródeł słownika SPXVI ${ }^{4}$. Leksem wyleganiec poświadczony jest też w prawniczym słowniczku Jana Cervusa z 1531 roku [Jankowiak, Łuczak, $\mathrm{w}$ druku]. W SJPXVIII wyleganiec nie jest już rejestrowany. W wariancie z nosówką wylęganiec 'bękart' notuje wyraz dopiero SWil, z adnotacją, że jest on nieużywany. Niepewna jest obecność tego wyrazu w gwarach. Rembiszewska podaje, że wyleganiec w znaczeniu 'łagas [sic!], znajdek' rejestruje Stownik gwar polskich za „Rocznikiem Poznańskiego Towarzystwa Przyjaciół Nauk”, tylko to poświadczenie ma kartoteka Słownika w Instytucie Języka Polskiego w Krakowie [Rembiszewska 2008: 60]. Nie wymienia tego wyrazu w książce Tabu w dialektach polskich Anna Krawczyk-Tyrpa [2001] ani w artykule Przemiany językowo-kulturowe wsi na przykładzie ekspresywizmów określajacych dzieci Anna Piechnik [2013]. Nie jest jasna geneza tej nazwy: Sstp ma hasło

4 Słownik z 1544 roku nie wszedł do kanonu źródeł SPXVI, ponieważ został odkryty dopiero na początku lat 70. XX wieku przez Irenę Kwilecką. Stopniowo jednak, jak odnotowuje Lucyna Agnieszka Jankowiak, wykorzystywany jest w słowniku, choć rzadko, jako źródło dodatkowe [Jankowiak 2017: 12, 14]. 
wylęganie 'miejsce do leżenia, legowisko, posłanie'. Skojarzenie z wylęgać jest jednak raczej wtórne - w jego wyniku nowsze źródła leksykograficzne podały wariant z nosówką, a więc wylęganiec (tak np. w SWil i Stowniku staropolskim Arcta [1920]). Bardziej prawdopodobne wydaje się słowotwórcze i semantyczne powiązanie tej nazwy z legać, lec, legający, które w XVI-wiecznej polszczyźnie oznaczały stosunek płciowy ${ }^{5}$ [zob. SPXVI]. Jeśliby oceniać stylistyczną wartość wyrazu wyleganiec, to ze względu na zakres występowania, ograniczony do ortyli, staropolskiego przekładu Biblii oraz słowników dwujęzycznych, wydawałby się raczej jednostką z rejestru oficjalnego. Trudno byłoby znaleźć argumenty za jego potocznym, ekspresywnym charakterem, chyba że byłyby to argumenty pozajęzykowe, związane ze społecznym statusem dziecka spoza małżeństwa.

Ciekawie przedstawia się porównanie dystrybucji wyrazów wyleganiec i pokrzywnik w tekstach staropolskich. Sstp zarejestrował wyraz pokrzywnik pięć razy ( $\mathrm{w}$ tym w wariancie z przestawką koprzywnik), zawsze w postaci glosy, a więc w kontekście zdania łacińskiego, w tym czterokrotnie jako glosę w opisach spraw sądowych. Są to sprawy o obelgi - pozwy dotyczą zniesławiania m.in. przez nazywanie kogoś pokrzywnikiem.

Mathias...proposuit contra eosdem, quomodo ipsi...infamaverunt ipsum infamacionibus pessimis, asserentes et nominantes ipsum fore furem, latronem, crematorem, male progenitum al. pokrzywnikiem 1462 MMAe XVI nr 827. [Sstp]

Nobilis Petrus...contra...Iohannem... pro eo, ....quod ei maledixit asserens ipsum koprzywnik et filium meretricis 1431 StPPP VII 344. [Sstp]

Pro eo, quod dixit (sc. Niemierza) patri suo (sc. Vinctentii), quod esset de malo thoro filius, de matre non copulate et esset spurio al. pokrzywnik 1434 AKH 341, sim.ib. [Sstp]

Z tego porównania wynikałoby, że wyleganiec był nazwą oficjalną i terminem prawnym, pokrzywnik zaś - określeniem potocznym, odbieranym jako wyzwisko. Być może jako wyraz spoza oficjalnego rejestru pominął pokrzywnika Bartłomiej z Bydgoszczy, nie zapisując go w żadnym ze swoich słowniczków [Kędelska, Kwilecka, Łuczak 2009]. Nie ma pokrzywnika również w leksykonie łacińsko-polskim Jana Mączyńskiego ani w słowniku Grzegorza

5 Na możliwość takiej interpretacji zwróciła mi uwagę dr Krystyna Data. 
Knapskiego. O potocznym charakterze tego wyrazu świadczy metajęzykowa uwaga zawierająca stylistyczną kwalifikację w Worku Judaszowym Sebastiana Klonowica. W obszerniejszym kontekście, którego nie uwzględnia SPXVI, mowa jest o mężatkach oszukujących naiwnych mężów, którzy, nieświadomi, wychowują nie swoje dzieci. Analogię dla nich znajduje autor w świecie przyrody: ptaki, zwane pokrzywkami, opiekują się wyklutymi z podrzuconych jajek kukułczętami. Taka jest domena źródłowa metafory:

Ach coż takich pokrzywek i grzywaczow durnych, / Ktory cudzołożników i czuryłow jurnych / Bękarty podrzucone grzeją, karmią, pieszczą. / [...] Karmią bękarty od żon zmamieni mężowie (Pokrzywnikami Polak takie dziecka zowie) (marg.) Pokrzywnicy abo bękarci. [Klonowic 1600: 61]

Argumentem za potocznością pokrzywnika może być również geneza tej nazwy, u której podstaw znajduje się analogia do świata zwierzęcego [Tokarski 1991:151].

Pokrzywka podrzucone kiedy kukułczęta / Wylęże: zaniedbawa swe własne ptaszęta: / Bo bastrowie więtszy są, łakomi i duży [...] / Ojcowicowie drobni, spokojni, pokorni: / Bastrowie są szczęśliwi, swowolni, uporni. [Klonowic 1600: 61]

Świadectwo Klonowica ma szczególną wartość, ponieważ jedyne dwa przykłady użycia, które zarejestrował SPXVI, to właśnie cytaty z Worka Judaszowego. Tylko ten przykład podaje też Samuel Bogumił Linde [SL, hasło pokrzywa]. Dzięki Klonowicowi udało się objaśnić genezę tej nazwy, na jego świadectwie oparli się autorzy SPXVI, natomiast wcześniejsze próby wyjaśnienia etymologii pokrzywnika, m.in. przez Aleksandra Brücknera, dowodzą, że świadomość pochodzenia tej nazwy zatarła się. Brückner podaje nazwę pokrzywnik „do dziś narzeczowe; nie dlatego że «w pokrzywach spłodzony», co byłoby gustem osobliwszym, lecz dla przesądu, że kobieta po akcie mokrząca na pokrzywy płodu pozbędzie" [Brückner 1927: 23-24]. Oprócz pokrzywnika mamy z XVI wieku poświadczoną również formę pokrzywnię, którą jako ekwiwalent łac. nothus, spurius, incerto patre procreatus wprowadził w swoim dykcjonarzu Mikołaj Volckmar [SPXVI, hasło pokrzywnię].

Ani pokrzywnik, ani pokrzywnię nie są rejestrowane w SJPXVIII. Pokrzywnik jako nazwa dziecka nieślubnego znana jest natomiast we współczesnych gwarach [Rembiszewska 2008: 59]. 
Wątpliwości może budzić również kwalifikowanie wyrazu bękart jako mającego wydźwięk negatywny od początku funkcjonowania w polszczyźnie. Jeśli wnioskować na podstawie frekwencji przykładów zarejestrowanych w Sstp, zapożyczenie to było rzadziej używane niż rodzime wyleganiec i pokrzywnik. Odnotowano trzy przykłady, w tym jeden w ortylu jako dopowiedzenie do wyleganiec: ,iż jest wyleganiec albo bękart OrtMac” oraz jako ekwiwalent łacińskich bastardus i spurius: „bękart bastardus; baster, bękart spurius ca 1500 Erz 3" [Sstp, hasło bękart]. Oczywiście na tej podstawie trudno coś więcej powiedzieć na temat wartości stylistycznej, przynależności do wysokiego lub niskiego rejestru. Na pewno nie można zinterpretować bękarta jako synonimu, który doprecyzowuje znaczenie wyrazu wyleganiec (choć byłaby to interpretacja pociągająca ze współczesnego punktu widzenia), ponieważ wyleganiec występuje w ortylach często, bękart zaś tylko ten raz.

Nieco więcej przesłanek pozwalających stylistycznie dookreślić bękarta znajdziemy w źródłach XVI-wiecznych. Wyraz ten notujemy w ówczesnych opisach prawa magdeburskiego, bardzo często u Pawła Szczerbica, wyjątkowo u Bartłomieja Groickiego: „,...] według prawa pisanego bękarci nie dziedziczą” [Szczerbic 1581: 114]; „Bękart nie może mieć dzieci dobrego łoża” [Szczerbic 1581: 103]; „Bękart nie zostawia dzieci dobrego łoża” [Szczerbic 2011: 208]; „Bękart jako się może dobrym stać” [Szczerbic 2011: 33] itp. Natomiast u Groickiego tylko jako hasło indeksowe w Rejestrze rzeczy i słów: „Bękartów różnych różne prawa” [Groicki 1562], a więc jako odsyłacz mający ułatwić odszukanie informacji dotyczących praw potomstwa pozamałżeńskiego (jest to przykład nieodnotowany przez SPXVI, ponieważ Rejestr stanowił dodatek do jednego z późniejszych wydań Porzadku sądów i spraw miejskich, nieuwzględnionego w źródłach słownika). SPXVI odnotował inny przykład: „A stądże też bękarci wedle prawa miejskiego mają krewne/ ale po wrzecienie nie po mieczu" [SPXVI, hasło bękart]. Wynika z tego, że w XVI-wiecznej polszczyźnie bękart był stosowany jako wykładnik pojęcia prawnego, a więc termin prawny.

O jego oficjalnym charakterze świadczy również obecność w przekładach biblijnych fragmentu Hebr 12,8 - Szymona Budnego, Marcina Czechowica oraz Biblii gdańskiej:

Co jeśli bez kaźni jesteście, której uczestniki bywają wszytcy, to bękarci jesteście, a nie synowie. [Budny 1574]

Co jeśli okrom karnienia jesteście, której uczestniki bywają wszyscy, to bękarci jesteście, nie synowie. [Budny 1572] 
A jeśli jesteście bez karania, którego zstali sie wszyscy uczestnikami, tedyć bękarty jesteście, a nie synami. [Czechowic 1577]

A jeśli jesteście bez karania, którego wszyscy są uczestnikami, tedyście bękartami, a nie synami. [Biblia gdańska 1532]

Jeśli chodzi o źródła XVI-wieczne, to warto również zwrócić uwagę na publikację Erazma Glicznera Książki o wychowaniu dzieci, w której nazwę bękart stosuje się wymiennie z różnymi wariantami o charakterze analitycznym, np. „W miastach też ten obyczaj urodził się, iż bękartowie rzemięsła nie mogą robić” [Gliczner 1558: B4v]; ,Coż tedy bękart gdy z nieuczciwego łona się pocznie, izaż ma być człowiekiem świetnem?" [Gliczner 1558: B5v]; „Amazones [...] puściły też o sobie tę wieść, iż ich przodek miał być Mars [...] a to dlatego aby postronne nacyje nie rozumiały je być bękartkami" [Gliczner 1558: B5v]; a także: „Ale nie telko te przykłady za naszą rzeczą stoją, którą powiadamy, że płod nieprawy nie tylko u ludzi, ale też i u Boga mało miejsca ma” [Gliczner 1558: B4v]; „Dał [Bóg] tę nam naukę i przykład w tem, że ci wszytcy ludzie, którzy się z nieuczciwego łona rodzą [...]" [Gliczner 1558: B4]. Poza wymienionymi w powyższych przykładach na oznaczenie dzieci spoza związku małżeńskiego spotkamy u Glicznera takie wyrażenia opisowe, jak: z nieuczciwego łoża syn, płod niewłasnej żony (o Izmaelu), nieprawi synowie, ludzie niepewnego ojca, niepewnego a niepoczciwego łona. Ta wymienność z nazwami analitycznymi, które bylibyśmy skłonni łączyć z rejestrem oficjalnym, świadczyłaby o takim również charakterze wyrazu bękart.

W tym czasie wartość ekspresywną miały, jak się wydaje, zdrobnienia, np. bebiś, bękarcięta. Gliczner np. wprowadza zdrobnienie bebiś, gdy mówi o potomkach osób duchownych, skrywających fakt ojcostwa:

A zaiste na tem mizernym a pochylnym świecie dosyć barzo potrafi ojców niepewnych, synów bez ojca. I zawadza się to nie telko miedzy pany a ludźmi świeckiemi, ale i księża, iż jako oni mżyk grają z swemi bebisiami, takci iż mam tak rzec swojemi bastertami, i nie chcą się s nimi wyrwać, wystąpić ani czuć $[. .$.$] bierzą pospolicie a przywłaszczają takowe sobie za synowce$ i siestrzanki, iż gdy ich kto zopyta, czyje by to były dzieci, wnet prząc się ich składają na przyjacioły i siostry, mówiąc: na opiekem to wziął a pracę swoję, chcąc się siestrze albo wujowi zachować. [Gliczner 1558: B5]

Co ciekawe, również forma bękarcięta (w 1m., por. bękartowie) w innych XVI-wiecznych źródłach występuje w związku z krytyką niepożądanych oby- 
czajów księży: „w plebanijej bękarciąt pełno OrzRozm 112v” [SPXVI, hasło bękarcię]; „Dionisia Kiermasz, mięsopusty, gdy sie ono popy na jedne niszą zjeżdżają i do jednej karczmy, z swemi kucharkami i bękarcięty Calep 326b" [SPXVI, hasło bękarcię]. W satyrycznym kontekście obecna jest też w Worku Judaszowym Klonowica: ,już sławę i dobra zepsuje do szczęta / Jeśli Pani uczynna rodzi bękarcięta" [Klonowic 1600: 59].

Przeprowadzona analiza nasunęła następujące wnioski:

A. O ile dosyć łatwo jest wskazać słownictwo prawne oddające pojęcie dziecka spoza związku małżeńskiego, przyjmując założenie, że terminami prawnymi są nazwy występujące w tekstach prawnych [Woźniak 2017], o tyle zakwalifikowanie omawianych jednostek jako potocznych lub nie - nie jest wolne od wątpliwości. Status oficjalności można przypisać nazwom o charakterze analitycznym, dla których da się wskazać źródło łacińskie. Wydaje się jednak, że i wśród nazw jednowyrazowych obserwujemy już w dobie staropolskiej warianty należące do różnych rejestrów stylistycznych. Świadczyłby o tym odmienny rozkład tych nazw w tekstach czy wypowiedziach powstałych w innych sytuacjach komunikacyjnych, a zwłaszcza fakt rozłączności zakresów występowania, co można było zaobserwować w staropolskich przykładach wyleganiec i pokrzywnik. Kilka wyrazów, które Rejter zaliczył do ekspresywizmów, należałoby wyłączyć z tej grupy, na pewno nazwę wyleganiec. W wypadku innych, np. bękarta, trzeba by uwzględnić zmianę nacechowania stylistycznego o charakterze degradacji, która dokonała się być może dopiero w XVII wieku. Natomiast wiele argumentów potwierdza potoczność nazwy pokrzywnik, np. to, że występuje ona w opisach spraw sądowych o zniesławienie, kiedy wskazuje się przyczyny pozwów. W przypadku pokrzywnika jesteśmy też w komfortowej sytuacji posiadania świadectwa $\mathrm{z}$ epoki w postaci metajęzykowego komentarza, określającego zakres stosowania nazwy. Dodatkowym argumentem może być ujawniające się w tej nazwie degradujące porównanie do świata zwierzęcego.

B. Z jednej więc strony rozłączność obszarów występowania wyrazów wyleganiec i pokrzywnik $\mathrm{w}$ dobie staropolskiej świadczyłaby o różnicowaniu rejestrów stylistycznych w zasobie leksykalnym już w tym czasie. Brak potwierdzenia, że toczono sprawy sądowe o zniesławienie z powodu nazwania kogoś wylegańcem czy bękartem to raczej nie przypadek, zwłaszcza że kilkakrotnie poświadczono w takim kontekście pokrzywnika. Jak wykazano, już dobę staropolską znamionuje obecność wariantów fonetycznych czy fleksyjnych uznawanych za lepsze i z tego powodu wprowadzanych do tekstów o wyższej randze, co stanowiło argument w dyskusji nad pochodzeniem polskiego języka literackiego [np. Walczak 1993: 27-28]. Może to być przesłanka 
do uznania podobnego zróżnicowania również w sferze leksyki. Z drugiej jednak strony doświadczenie każe zachować ostrożność w doszukiwaniu się w przeszłości takich podziałów, z jakimi mamy do czynienia dzisiaj. Zwracał na to uwagę Marek Cybulski, analizując teksty średniopolskie:

Porównując bowiem dawne i dzisiejsze zjawiska kulturowe, nieraz widzimy różnicę polegającą na tym, że dawniej nie różnicowano zjawisk, które rozdziela się dziś. Nie rozdzielano jasno np. tego, co świeckie i duchowne, cywilne i wojskowe, oficjalne i prywatne, państwowe i rodzinne itp. [Cybulski 2013: 30]

Ostre rozgraniczanie potoczności i oficjalności w dawnej, a zwłaszcza w najdawniejszej polszczyźnie, na podobieństwo współczesnego języka może mieć charakter nieuprawnionej projekcji. Analiza kilku wybranych nazw dzieci pozamałżeńskich, a także sposobu ich kwalifikowania w opracowaniach historycznojęzykowych pokazuje, jak trudno uwolnić się w myśleniu o dawnej leksyce, a zwłaszcza o jej stylistycznym nacechowaniu, od współczesnego poczucia językowego. Przejawia się to w skłonności do przypisywania wyrazom takiej wartości stylistycznej, jaką mają we współczesnej polszczyźnie, co widać choćby na przykładzie wyrazu bękart.

\section{Bibliografia}

\section{Slowniki}

SJPXVIII - Elektroniczny słownik języka polskiego XVII i XVIII wieku, http://sxvii.pl/ [dostęp: 25 września 2017]

SL - Linde Samuel Bogumił (1811), Stownik języka polskiego, t. 2, w Drukarni XX. Pijarów, Warszawa.

SPXVI - Pepłowski Franciszek, red. (1967, 1998), Stownik polszczyzny XVI wieku, t. 2, Zakład Narodowy im. Ossolińskich, Wydawnictwo Polskiej Akademii Nauk, Wrocław; t. 26, Instytut Badań Literackich Polskiej Akademii Nauk, Warszawa, http://kpbc.umk.pl/dlibra/publication?id=17781 [dostęp: 16 maja 2017].

SPXVIe - Stownik polszczyzny XVI wieku, edycja internetowa http://www.spxvi.edu. pl/indeks/ [dostęp: 15 maja 2017].

SPJS - Sieradzka-Baziur Bożena, red., Stownik pojęciowy języka staropolskiego, http:// spjs.ijp.pan.pl/ukladSemant/index/222 [dostęp: 27 listopada 2016]. 
Sstp - Urbańczyk Stanisław, red. (1972, 2002), Słownik staropolski, t. 6, Zakład Narodowy im. Ossolińskich, Wydawnictwo Polskiej Akademii Nauk, Wrocław, t. 10, Polska Akademia Nauk, Instytut Języka Polskiego, Kraków.

SWil - Stownik języka polskiego, wyd. Maurycy Orgelbrand, Wilno 1861, https://eswil. ijp.pan.pl [dostęp: 15 maja 2017].

\section{Literatura}

Arct Michał (1920), Stownik staropolski, oprac. Antoni Krasnowolski, Władysław Niedźwiedzki, Wydawnictwo M. Arcta, Warszawa, http://bc.wbp.lublin.pl/dlibra/ docmetadata? $\mathrm{id}=3296 \&$ from=pubstats [dostęp: 15 maja 2017].

Biblia gdańska (1632), Biblia Święta, to jest księgi Starego y Nowego Przymierza z Żydowskiego y Greckiego Języká ná Polski pilnie y wiernie przettumáczone, https://tinyurl.com/yaze93ys [dostęp: 25 września 2017].

Bily Inge, Carls Wieland, Gönczi Katalin (2011), Sächsisch-Magdeburgisches Recht in Polen, Berlin, http://books.google.pl [dostęp: 24 listopada 2016].

Brückner Aleksander (1927), Słownik etymologiczny języka polskiego, Krakowska Spółka Wydawnicza, Kraków.

Budny Szymon, przeł. (1574), Nowy Testament znowu przełożony, [Łosk] http://www. wbc.poznan.pl/Content/120603/index.djvu [dostęp: 16 maja 2017].

Budny Szymon, przeł. (1572), Biblia. To iest ksiegi stárego y nowego przymierza znowu z ięzyka Ebreyskiego, Greckiego y Łácińskiego ná Polski przełożone, Nieśwież, http://www.dbc.wroc.pl/dlibra/docmetadata?id=4263\&from=publication [dostęp: 25 września 2017].

Cybulski Marek (2013), Relacje między odmianami stylowymi języka doby średniopolskiej, „Rozprawy Komisji Językowej Łódzkiego Towarzystwa Naukowego”, s. 21-32.

Czechowic Marcin, przeł. (1577), Nowy Testament. To iest Wszytkie pisma nowego Przymierza z Greckiego ięzyká ná rzecz Polska wiernie y szczerze przełożone, [Kraków] https://polona.pl/item/42154384/0/ [dostęp: 25 września 2017].

Gliczner Erazm (1558), Ksyąszki o wychowanyu dzyeći bárzo dobre, pożyteczne y potrzebne, s ktorych rodzicy ku wychowanyu dzyeći swych náukę dołożna wyczerpnać moga, Kraków, http://www.dbc.wroc.pl/dlibra/doccontent?id=2579 [dostęp: 18 maja 2017].

Groicki Bartłomiej (1562), Porzadek Sadów y spraw Mieyskich Prawa Maydeburskiego na wielu mieyscach poprawiony, [Jan Januszowski] [Kraków] [i.e. ca 1582], wyd. C, http://dbc.wrc.pl: 11881 [dostęp: 25 września 2017].

Jankowiak Lucyna Agnieszka (2017), Słowniki Bartłomieja z Bydgoszczy (1532 i 1544). Stan badań i perspektywy badawcze, „Poznańskie Studia Polonistyczne. Seria Językoznawcza", t. 24, nr 1, s. 11-26. 
Jankowiak Lucyna Agnieszka, Łuczak Arleta (w druku), Miejsce nazw związanych z rodzina w stownikach Barttomieja z Bydgoszczy (1532 i 1544) - uwagi wstępne.

Kędelska Elżbieta, Kwilecka Irena, Łuczak Arleta, oprac. (2009), Stownik Barttomieja z Bydgoszczy: wersja polsko-tacińska, cz. 4, Slawistyczny Ośrodek Wydawniczy, Warszawa, http://rcin.org.pl/dlibra/doccontent?id=36029 [dostęp: 25 września 2017].

Klonowic Sebastian (1600), Worek Iudaszow. To iest złe nábycie Májętności, Kraków, http://www.dbc.wroc.pl/dlibra/doccontent?id=4268 [dostęp: 15 marca 2017].

Korpus tekstów staropolskich (2017), https://ijp.pan.pl/images/ publikacje_elektroniczne/korpus_tekstow_staropolskich/OrtMac.pdf [dostęp: 15 maja 2017].

Krawczyk-Tyrpa Anna (2001), Tabu w dialektach polskich, Wydawnictwo Akademii Bydgoskiej im. Kazimierza Wielkiego, Bydgoszcz.

Kresa Monika (2014), Bękart versus dziecko naturalne - różne sposoby mówienia o dzieciach zrodzonych poza zwiazkiem malżeńskim (XVI-XXI wiek), w: Bogactwo polszczyzny w świetle jej historii, t. 5, red. Joanna Przyklenk, Wydawnictwo Uniwersytetu Śląskiego, Katowice, s. 154-169.

Piechnik Anna (2013), Przemiany językowo-kulturowe wsi na przyktadzie ekspresywizmów określających dzieci, „Rozprawy Komisji Językowej Łódzkiego Towarzystwa Naukowego", s. 227-236.

Rejter Artur (2006), Leksyka ekspresywna w historii języka polskiego. Kulturowo-komunikacyjne aspekty potoczności, Wydawnictwo Uniwersytetu Śląskiego, Katowice.

Rembiszewska Dorota (2008), Nazwy nieślubnego dziecka w historii i dialektach polszczyzny, „Studia Germanica Gedanensia”, t. 16, s. 57-66.

Szczerbic Paweł (1581), Speculum Saxonum albo Práwo Sáskie y Maydeburskie porządkiem obiecádlá z Łácińskich y Niemieckich exemplarzów zebrane, á ná Polski ięzyk z pilnościa y wiernie przełożone, Lwów, http://www.dbc.wroc.pl/ dlibra/doccontent?id=9309 [dostęp: 15 maja 2017]

Szczerbic Paweł (2011), Ius municipale, to jest prawo miejskie majdeburskie, nowo z łacińskiego i z niemieckiego na polski język z pilnościa i wiernie przełożone, wyd. Grzegorz M. Kowalski, Księgarnia Akademicka, Kraków.

Tokarski Ryszard (1991), Wartościowanie człowieka w metaforach językowych, „Pamiętnik Literacki”, z. 1, s. 145-157.

Urbańczyk Stanisław, Kyas Vladimir, wyd. (1965-1971), Biblia Królowej Zofii (szaroszpatacka) wraz ze staroczeskim przektadem Biblii, Zakład Narodowy im. Ossolińskich, Wrocław.

Walczak Bogdan (1992), Siedemnastowieczny styl niski (na przyktadzie , Liber chamorum" Waleriana Nekandy Trepki), w: Odmiany polszczyzny XVII w., red. Halina Wiśniewska, Czesław Kosyl, Wydawnictwo UMCS, Lublin, s. 181-189. 
Walczak Bogdan (1993), Komu zawdzięczamy polski język literacki, w: Język a chrześcijaństwo, red. Irena Bajerowa, Maria Karpluk, Zenon Leszczyński, Wydawnictwo Towarzystwa Naukowego Katolickiego Uniwersytetu Lubelskiego, Lublin, s. $23-42$.

Woźniak Ewa (2017), Od dzieci z nieprawego łoża do dzieci nieślubnych. $Z$ dziejów polskiej terminologii prawnej, „LingVaria”, nr 1, s. 151-164.

\section{Ewa Woźniak}

On stylistic differentiation of the old Polish lexicon - on the example of official and colloquial terms for illegitimate child

The author attempts to determine stylistically three old terms for extramarital child: wyleganiec, pokrzywnik and bekart. These words have been up to now classified as colloquial and expressive, with negative undertone. They appear separately in the Old Polish and $16^{\text {th }}$ century texts and are of different character. An abusive term pokrzywnik is recorded only in relation to defamation cases. Official terms wyleganiec and bekart are present in old legal texts, biblical translations and dictionaries. This regularity shows the beginning of stylistic differentiation in the Old Polish lexicon, however the author is aware that the difference between colloquial and formal terms in the past was not necessarily so sharp as it is today and we cannot attribute present meaning to the past lexicon.

KeYwords: history of the Polish language $\left(14^{\text {th }}-16^{\text {th }}\right)$; historical stylistics; vocabulary $\left(14^{\text {th }}-16^{\text {th }}\right)$; extramarital children.

dr hab. Ewa Woźniak, prof. nadzw. UŁ - Zakład Historii Języka Polskiego, Instytut Filologii Polskiej i Logopedii, Uniwersytet Łódzki; zainteresowania naukowe: historia języka polskiego, stylistyka historyczna, semantyka historyczna, terminologia prawna. 
